Authors have nothing to disclose with regard to commercial support.

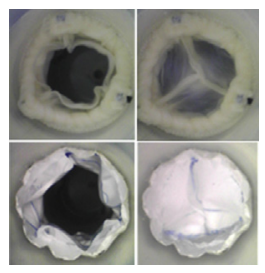

\section{AMPLIFYING ART OF VALVE DESIGN BY SCIENCE}

\section{To the Editor:}

Percutaneous pulmonary valve implantation has become one of the most promising surgical strategies for performing dysfunctional right ventriclepulmonary artery continuity reconstruction. Size limitations of the currently available valves for percutaneous pulmonary valve implantation application, however, hinder the treatment of many patients. ${ }^{1}$ Kan and colleagues $^{2}$ have proposed a design for handmade trileaflet-valved conduits with minimal size restriction and developed a tool to be used by surgeons to obtain optimal parameters before operation.

Such handmade expanded polytetrafluoroethylene (ePTFE) trileaflet conduits have been implanted in the pulmonary position since 1997 and have shown acceptable functional durability and expected performance, maintaining valve motion for as long as 10 years. ${ }^{3}$ Kan $^{1}$ further used the commercialized stent graft as the scaffold for compositing handmade trileaflet ePTFE valved conduits. Major vendors recommend selecting an oversized $(10 \%-20 \%)$ stent graft to avoid later migration. ${ }^{1}$ The diameter of the valve root, $\mathrm{D}^{\prime}$, determined by computed tomography or magnetic resonance imaging and the commissural coaptation height, $\mathrm{H}_{1}$, of the free edge of the valve leaflet are the only 2 parameters with which surgeons must be concerned (Figure 1,A). ${ }^{1}$ Once determined, a thin ePTFE membrane is trimmed into a semilunar tricuspid shape. ${ }^{1}$ Hammer and del Nido $^{4}$ disclosed valuable information: the free edge of a single leaflet

\footnotetext{
The Editor welcomes submissions for possible publication in the Letters to the Editor section that consist of commentary on an article published in the Journal or other relevant issues. Authors should: • Include no more than 500 words of text, three authors, and five references. • Type with double-spacing. • See http://jtcs.ctsnetjournals.org/ misc/ifora.shtml for detailed submission instructions. • Submit the letter electronically via jtcvs.editorialmanager.com. Letters commenting on an article published in the JTCVS will be considered if they are received within 6 weeks of the time the article was published. Authors of the article being commented on will be given an opportunity of offer a timely response ( 2 weeks) to the letter. Authors of letters will be notified that the letter has been received. Unpublished letters cannot be returned.
}

is both stretched and pulled downward from the commissures at peak diastole; this note inspired us to reconsider the possible influence from height adjustment of the free edge.

From stress-stretch study $^{5}$ and published anatomic study, ${ }^{6}$ while the aortic leaflet and attachment stresses reach maximum values at valve closure, the downward angle of the free edge, $\varphi$ (Figure 1, B), has been reported to be approximately $35^{\circ}$, and $\varphi$ decreased from $34^{\circ}$ to $24^{\circ}$ when diastolic pressure increased from $80 \mathrm{~mm} \mathrm{Hg}$ to $120 \mathrm{~mm} \mathrm{Hg}$. The ePTFE trileaflet conduits implanted in the pulmonary position should have a similar yet smaller angle change. The commissural coaptation height $\left(\mathrm{H}_{1}\right)$ of the free edge of the valve leaflet should therefore be adjusted significantly to have adequate commissural surface to prevent pulmonary regurgitation. Accordingly, in Kan's design, a jotting template of a handmade leaflet consists of geometric parabola details, including lower curved line, $\mathrm{C}_{1}$, and upper curved line, $\mathrm{C}_{2}$. In terms of valve leaflet opening (Figure 1,C), an endoscope inspection camera was deployed into a mock circulation loop, mounted with either a tissue valve (Epic; St. Jude Medical Inc, St Paul, Minn) or an ePTFE-valved conduit, to monitor valve motion. The video clips clearly showed that the trileaflet ePTFE-valve conduit's performance was not inferior to that of the commercial tissue valve. ${ }^{2}$ The computer-aided design procedure developed by Kan and colleagues ${ }^{1}$ in the article sheds light on the quantitative method to be the bridge from 2-dimensional handcrafted art to 3-dimensional computer-aided design science.

Wei-Ling Chen, $P h D^{a}$

Tsung-Lung Yang, $M D^{a}$

Chung-Dann Kan, $M D, P h D^{b}$

${ }^{a} K S V G H$ Originals \& Enterprises Kaohsiung Veterans General Hospital Kaohsiung, Taiwan

${ }^{b}$ Division of Cardiovascular Surgery

Department of Surgery

National Cheng Kung University Hospital College of Medicine

National Cheng Kung University Tainan, Taiwan

Supported by funding from the Medical Science and Technology Research Grant, National Cheng Kung University Hospital under contract number NCKUH10602002 . 


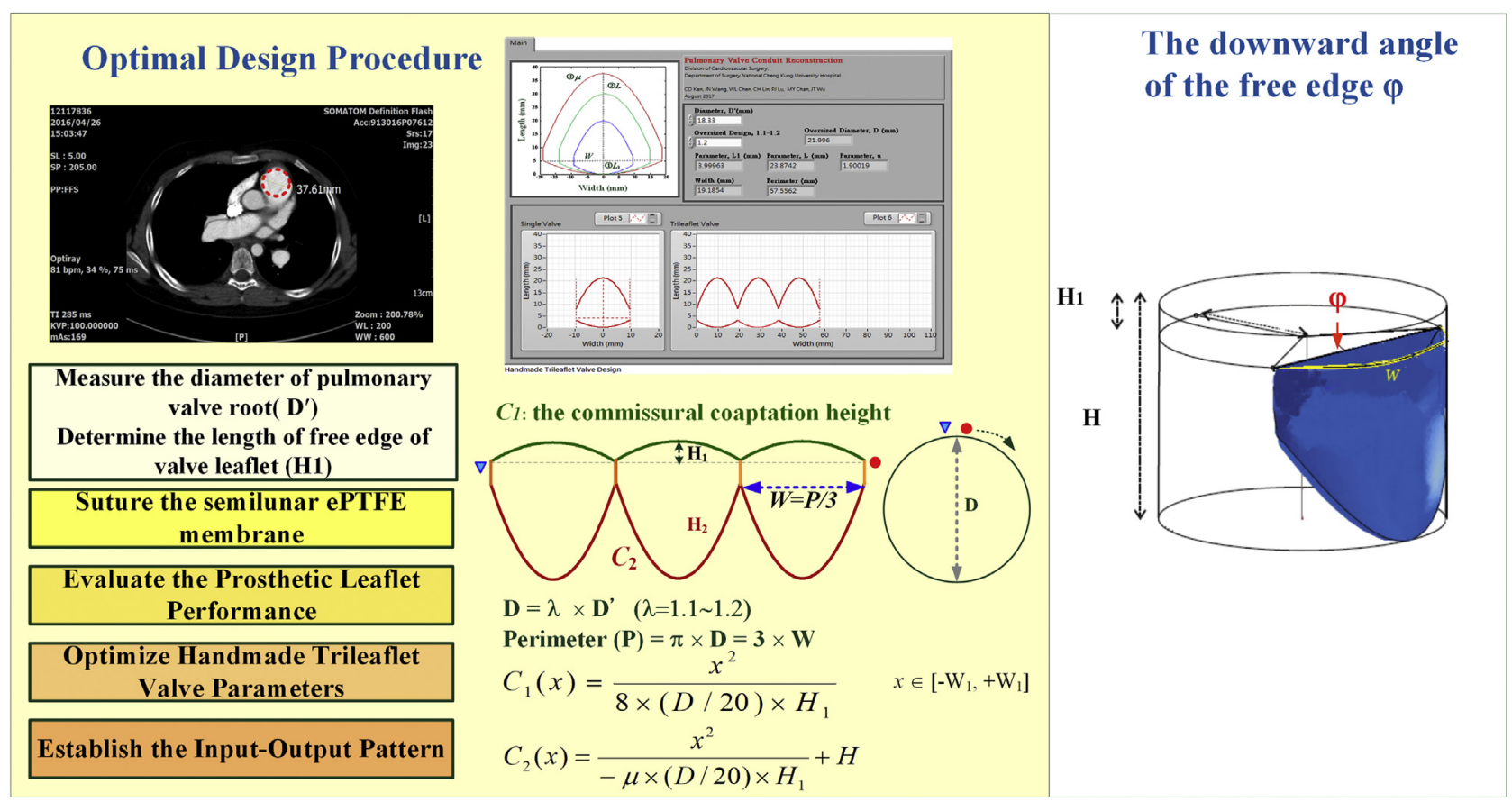

A

B

An endoscope inspection camera was deployed into mock circulation loop to monitor valve motion
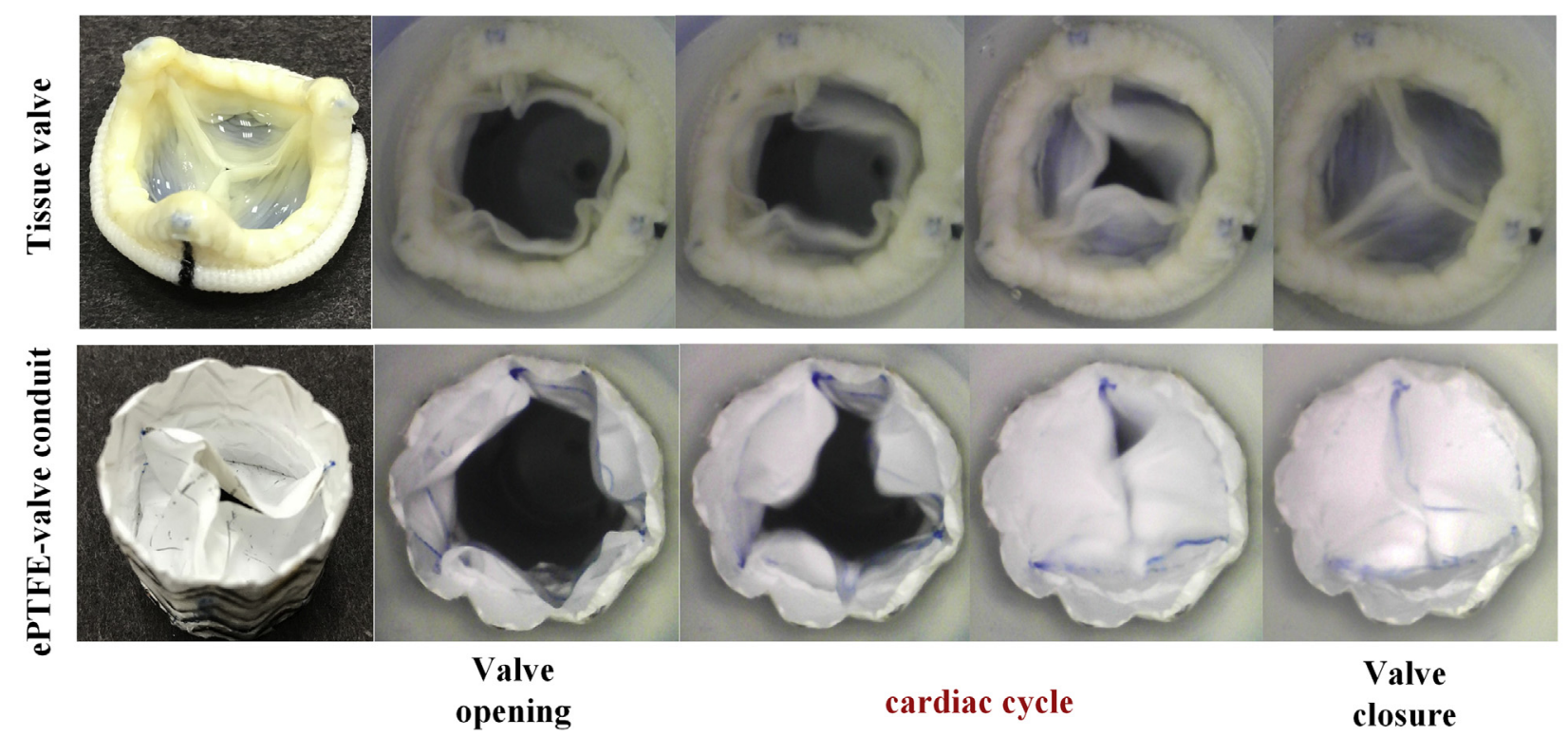

Valve
opening

cardiac cycle

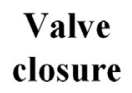

C

FIGURE 1. Handmade trileaflet valve design and its clinical application. A, Optimal design procedure. B, The downward angle of the free edge, $\varphi$. C, Comparison of a tissue valve (Epic; St. Jude Medical Inc, St Paul, Minn) and an expanded polytetrafluoroethylene valved conduit in the cardiac cycle.

\section{References}

1. Kan CD, Wang JN, Chen WL, Lu PJ, Chan MY, Lin CH, et al. Applicability of the handmade expanded polytetrafluoroethylene trileaflet-valved conduits for pulmonary valve reconstruction: an ex vivo and in vivo study. J Thorac Cardiovasc Surg. 2018;155:765-74.e3.

2. Kan CD, Chen WL, Lin CH, Wang JN, Lu PJ, Chan MY, et al. Handmade trileaflet valve design and validation for pulmonary valved conduit reconstruction using Taguchi method and cascade correlation machine learning model. IEEE Access. 2018;6:10381-91.
3. Ando M, Takahashi Y. Ten-year experience with handmade trileaflet polytetrafluoroethylene valved conduit used for pulmonary reconstruction. J Thorac Cardiovasc Surg. 2009;173:124-31.

4. Hammer PE, del Nido PJ. Guidelines for sizing pericardium for aortic valve leaflet grafts. Ann Thorac Surg. 2013;96:e25-7.

5. Loerakker S, Regento G, Oomens CW, Baaijens FP. Effects of valve geometry and tissue anisotropy on the radial stretch and coaptation area of tissue-engineered heart valves. J Biomech. 2013;46:1792-800. 
6. Swanson WM, Clark RE. Dimensions and geometric relationships of the human aortic valve as a function of pressure. Circ Res. 1974;35:871-82.

\section{https://doi.org/10.1016/j.jtcvs.2018.05.034}

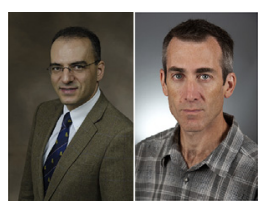

\section{INNOVATION AND} SCIENCE: THE FUTURE OF VALVE DESIGN

Reply to the Editor:

Designing semilunar valves in children has been a constantly evolving and at the same time challenging field for both the clinicians and the engineers involved. Recent approaches embraced include analytic methods based on engineering principles promising a more scientific and precision-based approach. This requires a solid understanding of the precise mechanisms of normal valve operation, but superimposed on this is the constantly changing environment of the valve due to the growing child, a change of hemodynamics, or a disease process that evolves over time.

This article by Chen and colleagues ${ }^{1}$ is another example of attempting to advance the science of designing valves using an analytic approach and engineering principles for which they need to be congratulated. They used a commercial stent graft as the scaffold for compositing handmade trileaflet expanded polytetrafluoroethylene valved conduits.

The work by Chen and colleagues ${ }^{1}$ takes steps toward understanding the relationship between the 2-dimensional shape of the valve leaflets and the closed and loaded 3dimensional shape of the valve for a given material using a computer-aided design. Understanding this relationship is essential for developing a repeatable procedure for valve reconstruction that achieves predictable valve function postoperatively. On the other hand, achieving predictable long-term valve function requires an understanding of several more complicated relationships. For example, the range of normal working stresses in the reconstructed valve and adjacent tissues must be known and related to the loads at which these materials and tissues fail. We are just beginning to compare the working stresses in the reconstructed valve with the stresses at which valve reconstruction materials fail, ${ }^{2}$ although this work just scratches the surface. Tissue stresses are also hypothesized to drive long-term biological responses, such as calcification and fibrosis, to valve reconstruction materials. Considerable work lies ahead to quantify these relationships so that they can be used to directly drive design. Finally, in the pediatric patient, repairing a valve with long-term durability requires
Authors have nothing to disclose with regard to commercial support.

understanding of and strategy for accommodating patient growth. Several preliminary concepts have been proposed to address the challenge of growth accommodating valve repair, ${ }^{3,4}$ but, again, much work remains to be done.

Pushing the frontiers in valve reconstruction requires both innovation and application of science, analytic methods, and engineering principles, combined with an understanding of the way the tissues and materials used behave over time. The final test of such designs still remains the human body itself and the unique ways it handles both the design of such valves and the tissues of which they are composed. Although clinicians, surgeons, and engineers have pushed the frontiers in this field, it is the harmonious and synergistic efforts of all that will push the field to the next level and the future of precision designed medicine.

\section{John M. Karamichalis, $M D^{a, b}$ \\ Peter E. Hammer, PhD ${ }^{c, d}$ \\ ${ }^{a}$ Pediatric Cardiac Surgery \\ The Children's Hospital at Saint Francis \\ Tulsa, Okla \\ ${ }^{b}$ Cardiac Surgery \\ Arkansas Children's Hospital \\ Little Rock, Ark \\ ${ }^{c}$ Department of Cardiac Surgery \\ Boston Children's Hospital \\ Boston, Mass \\ ${ }^{d}$ Harvard Medical School \\ Boston, Mass}

\section{References}

1. Chen W-L, Yang T-L, Kan C-D. Amplifying art of valve design by science J Thorac Cardiovasc Surg. 2018;156:1639-41.

2. Hammer PE, Baird CW, del Nido PJ, Marx GR. Dehiscence of patch augmentation of a left-sided atrioventricular valve related to strenuous isometric exercise: case report and failure analysis. J Thorac Cardiovasc Surg. May 3, 2018 [Epub ahead of print].

3. Feins EN, Lee Y, O'Cearbhaill ED, Vasilyev NV, Shimada S, Friehs I, et al. A growth-accommodating implant for paediatric applications. Nat Biomed Eng. 2017; 1:818-25.

4. Hammer PE, Roberts EG, Emani SM, del Nido PJ. Surgical reconstruction of semilunar valves in the growing child: should we mimic the venous valve? A simulation study. J Thorac Cardiovasc Surg. 2017;153:389-96.

https://doi.org/10.1016/j.jtcvs.2018.06.043 